\title{
The Werner Mutation: Does it Lead to a "Public" or "Private" Mechanism of Aging?
}

\section{George M. Martin}

Departments of Pathology and Genetics, University of Washington, Seattle, Washington, U.S.A.

The recent positional cloning (1) of the Werner helicase gene $(W R N)$, determining that the gene's mutations are responsible for the Werner syndrome (WS) ("progeria of the adult"; $\mathrm{McKu}$ sick \#277700) (2), has created a great deal of excitement among biogerontologists. A quotation in the popular press attributed to one of my colleagues suggested that this discovery was the "holy grail" of research on aging. Just how relevant is this line of research likely to be to our knowledge of human aging and age-related diseases? We do not yet know the answer to this question, but there are reasons for caution, in regard to both the clinical phenotype and the results of recent cell biological research.

\section{THE CLINICAL PICTURE OF THE WERNER SYNDROME}

Given the fact that we are dealing with a rare autosomal recessive disorder, one can often elicit a history of parental consanguinity, patients often being the progeny of matings between first cousins. A number of compound heterozygotes have already been identified, however, in which different mutations arose in each of the unrelated parental lineages (3). Given sufficiently large sibships, variable degrees of expression of the mutation can be seen in sisters and brothers who are homozygous for the mutation(s), the degree of expression being largely a function of chronological age. Differences in penetrance

Address correspondence and reprint requests to: George $M$. Martin, University of Washington, Dept. of Pathology, Box 357470, Seattle, WA 98195-7470, U.S.A. Tel: 206-5435088; Fax: 206-685-8356; e-mail: gmmartin@u.washington. edu. among sibs may also exist that are not related primarily to age, however, raising the interesting possibility that alleles at other loci may modulate expression to some degree. This is a subject deserving of careful research, research that should be greatly expedited by the availability of molecular diagnoses.

Although we lack reliable quantitative data on early development, the first evidence of a problem is the failure of WS subjects to undergo the usual adolescent growth spurt (4). Their adult stature is thus distinctly below that of unaffected family members. In usual aging, of course, short stature has an entirely different pathogenesis. Premature graying and thinning of scalp hair develops in the twenties, followed by bilateral cataracts, which are diagnosed at a median age of 30 years. The cataracts are said to be posterior subcapsular. While the morphologies of senescent cataracts in the general population are variable, they are more likely to be nuclear in origin. In usual aging, the pathogenesis of cloudy lenses is likely to be related to post-translational changes in lens crystallins (5), whereas in WS, given the evidence that we are dealing with a DNA helicase, the root of the problem is likely to be within the lens epithelial cells. Premature osteoporosis is common, but its distribution differs from that of usual aging in that it is more severe in the long bones of the limbs than in the spine. Type 2 diabetes mellitus occurs, but perhaps only in a third of patients. The remarkable severe ulcerations around the Achilles tendon and the malleoli seem to be different from the ulcerations one observes in diabetics and may be related in part to skin atrophy and the profound loss of subcutaneous tissues in the distal extremities. Moreover, I have seen patients with "punched- 
out" ulcerations around the elbows. These are associated with soft tissue calcifications. This phenotype is not observed in usual aging. Several forms of arteriosclerosis occur in WS, including medial calcinosis and atherosclerosis, the latter being the usual cause of death, at a median age of 47 (4). An unusual aspect of the cardiovascular pathology, however, is the extreme calcification of the heart valves and rings $(4,6)$. The benign and malignant neoplasms that are typical of WS are commonly of mesenchymal origins and include some very rare cancers, such as acral lentiginous melanomas, the frequencies of which may be more than 1,000 times that observed in the general population (7). Gonadal atrophy has been well characterized in males but less well studied in females. This results in marked reductions in fertility. WS therefore does not fit the evolutionary biological definition of aging (phenotypes that escape the force of natural selection) (8). It is possible, however, that "leaky" alleles may exist such that the features of the disorder do indeed become manifested after the peak of reproduction. To date, no such alleles have been identified $(1,3,9)$ but, on the other hand, those of us interested in the disorder have been seeking only the full-blown syndrome.

\section{THE CELL BIOLOGY OF THE WERNER SYNDROME}

In 1970, my colleagues and I reported that skin fibroblast-like cells from WS subjects have marked limitations of their replicative life spans-some 2 to 3 standard deviations below the means of those of cultures from age-matched controls (10). But are the mechanisms whereby WS leaves the cell cycle comparable to those of cells from these controls? Three lines of evidence suggest that the mechanism may indeed be distinct. First, whereas replicatively senescent cells from controls fail to respond to mitogenic stimulation via a pathway that induces the cfos transcription factor, senescent WS cells maintain that function (11). Second, the S phase of the mitotic cell cycle of WS cells is elongated and there is a tendency of cells to become arrested in the $S$ phase of the cell cycle (12). Third, senescent WS cells have telomeres that are, on average, longer than those of controls (13); loss of telomere repeats is thought by some to underlie the replicative declines of normal somatic cells. Thus, the mechanism of replicative senescence of WS cells may prove to be unique.

\section{"PUBLIC" VERSUS "PRIVATE" MECHANISMS OF AGING}

My colleagues and I have recently reviewed the literature on gene action underlying longevity and aging phenotypes (14). Two types of gene action are thought to underlie senescence; the phenotypic effects of both escape the force of natural selection. The first category involves a potentially large variety of individually rare, constitutional mutations whose effects do not reach some phenotypic threshold until after the peak of reproductive fitness. They can be considered "private" in the sense that they are idiosyncratic, being characteristic of particular population lineages. Their variable prevalences can be attributed to the effects of genetic drift. The second category involves gene variations whose effects are beneficial early in the life course but are deleterious postreproductively ("antagonistic pleiotropy" or "negative pleiotropy"). This second class of gene action can be considered to lead to "public" mechanisms of aging in that they would be presumed to be under strong selective pressure and, once selected, would be more likely to be maintained in multiple lineages. Polymorphisms, rather than mutations, are likely to be of greater relevance to our understanding of such public mechanisms of aging. I would tentatively conclude that the WS mutation is an example of a constitutional mutation leading to a "private" mechanism of age-related diseases. But here we have to be more careful to define our level of analysis of "mechanism." For example, there seems to be little doubt that somatic mutation is an important mechanism leading to the emergence of the neoplasms that become highly prevalent in older mammals. One has to ask about the precise molecular mechanism underlying such mutations, however, about which we need to know a great deal more. WS cells clearly exhibit a mutator phenotype, with a particular propensity for chromosomal lesions and intragenic deletions (15-19). Thus, at some level, the level of genomic instability, WS can inform us about aspects of the pathobiology of aging. We will need to know the precise function of the Werner helicase. Is DNA or RNA its preferred substrate? Is its principal role in replication, repair, transcription, recombination, chromosomal segregation, or combinations of these? How will these alterations compare with what is observed in the somatic cells from most aging subjects? A recent hint that such followups to the discovery of the $W R N$ gene may yet 
prove to be of general clinical relevance is the preliminary report of the association of a minor polymorphic form of the gene with relative resistance to myocardial infarction (20). That polymorphism was in the coding region, but it could conceivably be a surrogate for variations in regulatory domains of the gene that could potentially affect the speed and efficiency of the response of cells of the vascular wall to injury.

\section{REFERENCES}

1. Yu C-E, Oshima J, Fu YH, et al. (1996) Positional cloning of the Werner's syndrome gene. Science 272: 258-262.

2. http://www3.ncbi.nlm.nih.gov/omim.

3. Oshima J, Yu CE, Piussan C, et al. (1996) Homozygous and compound heterozygous mutations at the Werner syndrome locus. Hum. Mol. Genet. 5: 1909-1913.

4. Epstein CJ, Martin GM, Schultz, AL, et al. (1966) Werner's syndrome a review of its symptomatology, natural history, pathologic features, genetics and relationship to the natural aging process. Medicine 45: 177-221.

5. Stadtman ER, Oliver CN. (1991) Metal-catalyzed oxidation of protein. Physiological consequences. J. Biol. Chem. 266: 2005-2008.

6. Cohen JI, Arnett EN, Kolodny AL, et al. (1987) Cardiovascular features of the Werner syndrome. Am. J. Cardiol. 59: 493495.

7. Goto M, Miller RW, Ishikawa Y, et al. (1996) Excess of rare cancers in Werner syndrome (adult progeria). Cancer Epidemiol. Biomarkers Prev. 5: 239-246.

8. Rose MR. (1991) Evolutionary Biology of Aging. Oxford University Press, New York.

9. Yu CE, Oshima J, Wijsman EM, et al. (1997) Mutations in the concenus helicase domains of the Werner syndrome gene. Am. J. Hum. Genet. 60: 330-341.

10. Martin GM, Sprague CA, Epstein CJ. (1970) Replicative life-span of cultivated human cells. Effects of donor's age, tissue, and genotype. Lab. Invest. 23: 86-92.
11. Oshima J, Campisi J, Tannock TC, et al. (1995) Regulation of c-fos expression in senescing Werner syndrome fibroblasts differs from that observed in senescing fibroblasts from normal donors. J. Cell. Physiol. 162: 277-283.

12. Poot $M$, Hoehn H, Runger TM, et al. (1992) Impaired S-phase transit of Werner syndrome cells expressed in lymphoblastoid cell lines. Exp. Cell Res. 202: 267-273.

13. Schulz VP, Zakian VA, Ogburn CE, et al. (1996) Accelerated loss telomeric repeats may not explain accelerated replicative decline of Werner syndrome cells. Hum. Genet. 97: 750-754.

14. Martin GM, Austad SN, Johnson TE. (1996) Genetic analysis of ageing: Role of oxidative damage and environmental stresses. Nat. Genet. 13: 25-34.

15. Hoehn H, Bryant EM, Au K, et al. (1975) Variegated translocation mosaicism in human skin fibroblast cultures. Cytogenet. Cell Genet. 15: 282-298.

16. Salk D, Au K, Hoehn H, et al. (1981) Cytogenetics of Werner's syndrome cultured skin fibroblasts: Variegated translocated mosaicism. Cytogenet. Cell Genet. 30: 92-107.

17. Fukuchi K, Martin GM, Monnat RJ Jr. (1989) Mutator phenotype of Werner syndrome is characterized by extensive deletions. Proc. Natl. Acad. Sci. U.S.A. 86: 58935897.

18. Fukuchi K, Tanaka K, Kamahara $Y$, et al. (1990) Increased frequency of 6-thioguanine-resistant peripheral blood lymphocytes in Werner syndrome patients. Hum. Genet. 84: 249-252.

19. Runger TM, Bauer C, Dekant B, et al. (1994) Hypermutable ligation of plasmid DNA ends in cells from patients with Werner syndrome. J. Invest. Dermatol. 102: 45-48.

20. Ye L, Miki T, Nakura J, et al. (1997) Rapid publication: Association of a polymorphic variant of the Werner helicase gene with myocardial infarction in a Japanese population. Am. J. Med. Genet. 68: 494-498. 